\title{
Local temporal distinctiveness does not benefit auditory verbal and spatial serial recall
}

\author{
FABRICE B. R. PARMENTIER, SUZANNE KING, and IAN DENNIS \\ University of Plymouth, Plymouth, England
}

\begin{abstract}
In the present study, we examined the role of randomly arranged temporal intervals preceding and following items (pre- and postitem intervals, respectively) in auditory verbal and spatial recall tasks. The duration of the pre- and postitem intervals did not affect serial recall performance. This finding calls into question (1) the suggestion that the interval following an item permits the consolidation of information in memory, even in a relatively demanding spatial task, and (2) the prediction that temporal distinctiveness should improve performance. The latter was explored further by showing that in contrast to our empirical data, a relative temporal distinctiveness model produced significant increases in recall performance when pre- and postitem intervals increased. The results are discussed with regard to recent studies revisiting the role of temporal isolation in short-term serial memory.
\end{abstract}

The ability to process order information is an essential aspect of human cognition (see, e.g., Lashley, 1951) and a specific function of short-term memory (e.g., Ebbinghaus, 1885). That events are defined by their temporal context is not controversial, but the contribution of time per se to serial memory remains unclear. Current theories of serial memory can be separated into two broad categories: theories in which temporal information is viewed as an intrinsic part of the representation of information (timebased models; see, e.g., Brown, Preece, \& Hulme, 2000; Glenberg \& Swanson, 1986; Neath, 1993) and theories in which time is viewed merely as an opportunity to consolidate or rehearse information in memory and in which forgetting results from interference (event-based theories; see, e.g., Farrell \& Lewandowsky, 2002; Lewandowsky \& Murdock, 1989; Nairne, 1990; Neath, 2000).

One general assumption of temporal distinctiveness theories (e.g., Glenberg \& Swanson, 1986; Neath \& Crowder, 1990, 1996) and more recent time-based models of immediate memory is that the probability of recalling an item increases when this item is temporally isolated within the list. Many studies (e.g., Glenberg \& Swanson, 1986; Neath, 1993) have measured the temporal distinctiveness of an item as the ratio between the interval separating that item from the previous item (interpresentation interval, or IPI) and the time interval between that item and the time of recall (retention interval). This ratio rule accounts for recall accuracy reasonably well in experiments in which IPI values are manipulated across lists in

Part of this work was supported by Grant RES-000-22-0233 from the Economic and Social Research Council to the first author. We thank James Nairne, Steve Lewandowsky, Ian Neath, Lisa Nimmo, Jane Elsley, and one anonymous reviewer for their valuable comments on an earlier version of the manuscript. Correspondence can be sent to F. B. R. Parmentier, School of Psychology, University of Plymouth, Drake Circus, Plymouth PL4 8AA, England (e-mail: fabrice.parmentier@plymouth.ac.uk). a predictable fashion (e.g., Bjork \& Whitten, 1974; Neath \& Crowder, 1990, 1996), but the effect of temporal distinctiveness has been questioned in a number of studies in which unpredictable interitem intervals have been used (e.g., Lewandowsky, Brown, Wright, \& Nimmo, 2006; Nimmo \& Lewandowsky, 2005, in press).

The notion that temporal isolation makes items stand out and increases their probability of being recalled is present in many recent time-based models of immediate memory, such as temporal oscillator models (e.g., Brown et al., 2000; Burgess \& Hitch, 1999) or the scale invariant memory, perception, and learning (SIMPLE) model (Brown, Neath, \& Chater, 2006). In contrast to the ratio rule of early temporal distinctiveness theories, recent time-based models (e.g., SIMPLE) are relative models, in the sense that they assess the temporal confusability of an item with a neighboring item relative to its confusability with any other item in the list. ${ }^{1}$ In conclusion, temporal distinctiveness can be defined locally (e.g., Glenberg \& Swanson, 1986; Neath \& Crowder, 1990, 1996) or globally (Brown et al., 2005).

Interestingly, the local impact of time on serial memory does not necessarily reflect the impact of time per se but, possibly, the opportunity to encode or consolidate information in memory. A recent study by Lewandowsky and Brown (2005) supported the latter contention. These authors used visually presented sequences of nine consonants constructed so that the interitem intervals varied quasirandomly. Performance at Serial Positions 2, 4, 6, and 8 was analyzed with regard to two predictors: the durations of pre- and postitem intervals. The results showed that the duration of the preitem interval played no role in recall accuracy but that performance increased as a function of the duration of the postitem interval. Because this effect disappeared in the presence of articulatory suppression, the authors suggested that the rehearsal or consolidation of information during the postitem interval, in the 
time available immediately after the presentation of an item, was responsible for the effect.

The aim of the present study was twofold. The first goal was to examine the impact of relative temporal isolation on serial recall performance. The second goal was to investigate further the contention that the postitem interval improves recall accuracy by enhancing memory consolidation. According to this view, allowing more time for consolidation should be especially beneficial for stimuli requiring more encoding effort. For the purpose of our experiment, we replicated the design used by Lewandowsky and Brown (2005) but compared memory for sequences of auditory verbal and spatial stimuli. Relatively little research is available on serial memory for auditory spatial stimuli, but there is evidence indicating that such stimuli entail lower accuracy levels than do auditory verbal stimuli, although exhibiting the typical characteristics of serial memory with regard to serial position effects and distribution gradients (Parmentier \& Jones, 2000) or the effect of temporal grouping (Parmentier, Maybery, \& Jones, 2004). Parmentier and Jones (2006) also suggested that the maintenance of such stimuli relies heavily on central attentional resources. Finally, some authors have argued that in the auditory domain, the encoding of spatial location is not automatic but only secondary (Kubovy \& Van Valkenburg, 2001), supporting the idea that the encoding of auditory locations may be relatively demanding. In summary, it may be particularly interesting to study the impact of temporal distinctiveness on serial memory, using auditory spatial stimuli because time arguably plays a prominent role in the absence of other factors typically involved in verbal memory tasks (e.g., the availability of well-practiced rehearsal strategies or support from longterm memory representations).

In the present study, the participants took part in two tasks. In the verbal task, they were required to recall the presentation order of auditory consonants coming from a single spatial location. In the spatial task, the participants were required to recall a sequence of bursts of white noise coming from a number of distinct spatial locations distributed around them. If temporal isolation benefits recall accuracy, performance should improve when the temporal separation of an item, relative to its neighbors, increases. Furthermore, if the time available to consolidate encoding mediates recall accuracy, recall performance should improve as a function of the duration of the postitem interval, but more so in the demanding spatial task than in the relatively easy verbal task.

\section{METHOD}

\section{Participants}

Twenty undergraduate students from the University of Plymouth participated in this study. All reported normal or corrected-tonormal vision and normal hearing.

\section{Materials and Stimuli}

Stimuli in the verbal task consisted of the digits $1-7$. The digits were recorded in a monotone female voice to avoid prosodic variations, digitally edited to $300 \mathrm{msec}$, and normalized. The adminis- tration of the verbal task took place in a quiet room, using a PC equipped with headphones. The stimulus used in the spatial task was a 300-msec burst of white noise. The spatial task took place in an anechoic chamber equipped with seven loudspeakers controlled by a PC equipped with an Echo Gina 24 sound card. The participants were seated at the center of the chamber and were surrounded by an array of loudspeakers arranged $30^{\circ}$ apart in the azimuth orientation $\left(-90^{\circ},-60^{\circ},-30^{\circ}, 0^{\circ},+30^{\circ},+60^{\circ}\right.$, and $+90^{\circ}$, where $0^{\circ}$ represents the direction facing the participant and negative and positive values represent locations to the left and right of the participant, respectively). The computer screen was located directly in front of the participants, underneath the front speaker.

Different sets of 120 sequences were built for each task and participant. Each sequence comprised the digits 1-7 (in the spatial task, these digits coded the seven spatial locations from left to right). Sequences were generated randomly, with the constraints that each digit should be used once only in each sequence and that ascending or descending groups (e.g., 12, 21, 23, etc.) were excluded. The duration of the interitem intervals varied randomly across sequences, with the constraints that the sum of all interitem intervals within a sequence was always $2,400 \mathrm{msec}$ and that the minimum and maximal durations of each interval were 50 and $950 \mathrm{msec}$, respectively. Descriptive statistics for the intervals are provided in Appendix A.

\section{Procedure}

The participants took part in two tasks, verbal and spatial, on separate days ( 1 week apart). Half the participants carried out the verbal task first. In both the verbal and the spatial tasks, the participants initiated a trial by clicking on a button displayed on the screen. When pressed, this button disappeared and was followed, 2,000 msec later, by the onset of the to-be-remembered sequence. The last item was followed by a 150 -msec interval, during which the screen remained blank, and then by the presentation of the response screen. In the verbal task, this screen contained buttons labeled with the digits 1-7 (in ascending order) in black, distributed horizontally across the screen. The participants were required to click on the labels in the order in which the digits had been presented. Once selected, each digit turned gray and could not be used again in that trial. As the participants recalled the digits, their responses filled a series of boxes at the top of the screen. A "skip" button was also available, which the participants were instructed to use if they could not remember or guess a particular item (if it was used, a "_" character appeared at the top of the screen, instead of a digit).

In the spatial task, the response screen was similar to that used in the verbal task with regard to the skip button and the series of boxes at the top of the screen. In this task, however, the participants clicked on a visual representation of the array of loudspeakers (each represented by a white square framed in black). Once selected, locations turned gray and were no longer available for selection on that trial. As in the verbal task, a series of boxes at the top of the screen were filled as responses were recorded (location responses were represented by “*” and omitted items by "_"). The participants performed the spatial task in the dark. They were instructed to fixate the computer screen during the presentation of the sounds and were informed that the experimenter would control compliance with this instruction through an infrared closed-circuit video link. The participants were encouraged to respond as accurately as possible and to respond as soon as they knew which item to recall. The participants were allowed a short break in each task after every 40 test trials.

\section{RESULTS}

This section is organized into three subsections. First, we checked that aspects of performance typically associated with serial memory (serial position effects, overall decreasing response latencies, and negatively accelerated 
distribution gradients) were present in our data. Second, we assessed the impact of pre- and postitem intervals on recall accuracy, using a method analogous to that in Lewandowsky and Brown (2005). Third, we compared our data with a simplified version of SIMPLE.

\section{Serial Memory Effects}

The analysis of accuracy levels confirmed that both the verbal and the spatial tasks exhibited standard serial position effects, as is illustrated in Figure 1 (panel A). Response latencies (see Figure 1, panel B) were longer in the spatial task. They decreased with serial position: sharply from Serial Position 1 to Serial Position 2, and then modestly across later positions, with a slight rebound in the spatial task. This pattern is in line with that observed in other serial memory studies (see Anderson \& Matessa, 1997; Maybery, Parmentier, \& Jones, 2002). Finally, the proportion of temporal errors decreased as a function of the temporal distance between the correct and the recalled positions (see Figure 1, panel C), following a negatively accelerated function typically observed in serial memory studies. The details of the analysis are reported in Appendix B.

\section{Effect of Temporal Distinctiveness}

Effect of pre- and postitem intervals on accuracy. A logistic regression was performed on each participant and task, with the score for each response ( 1 or 0$)$ as the dependent variable and the pre- and postitem intervals (coded in seconds) as predictors. To keep predictors independent and in line with Lewandowsky and Brown (2005), responses to Serial Positions 2, 4, and 6 only were used. Regression coefficients obtained for each predictor and participants were then compared with zero, using onesample $t$ tests. None of the comparisons proved signifi-
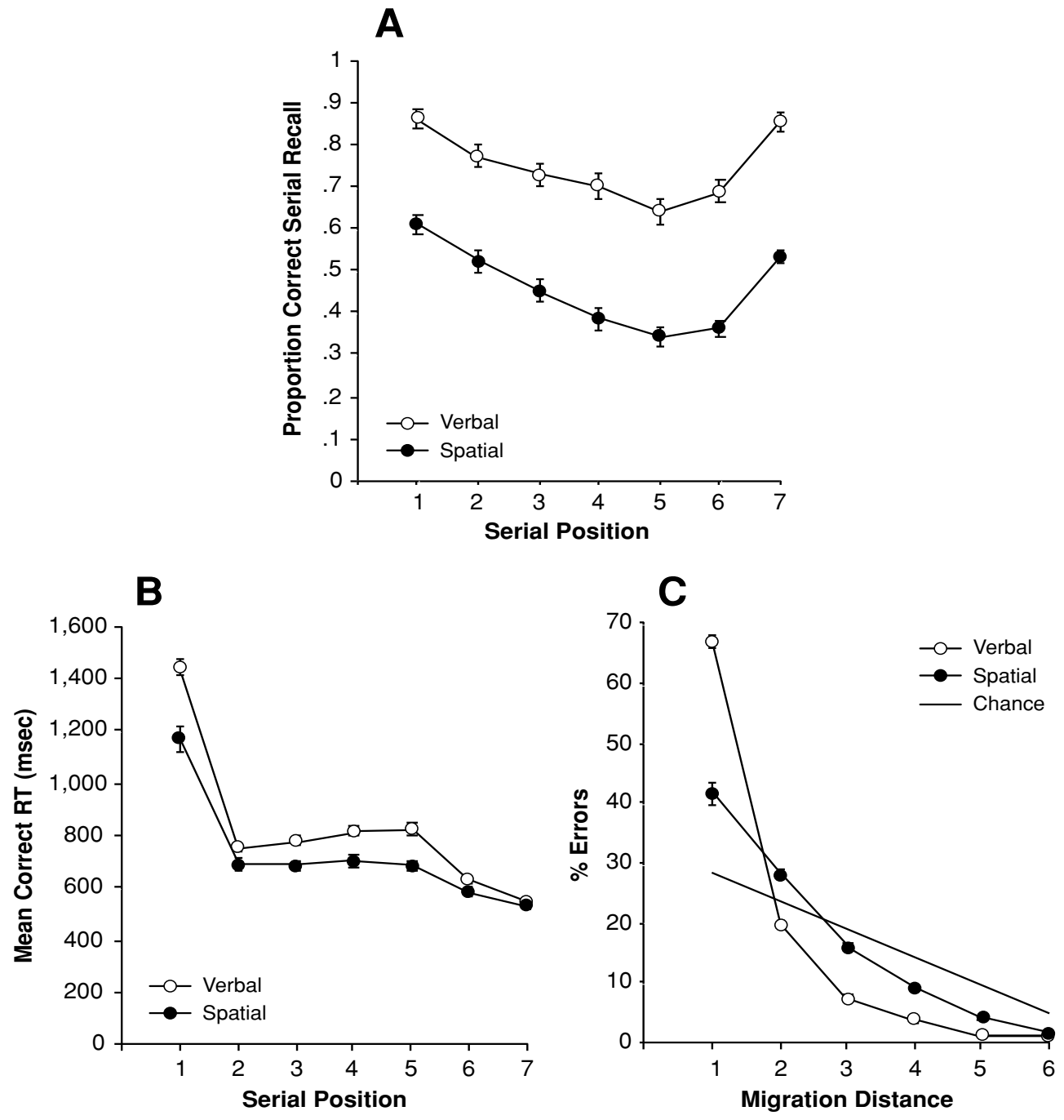

Figure 1. Measures of serial recall performance. (A) Mean proportion of correct recall as a function of serial position for the verbal and spatial tasks. (B) Mean response times for correct responses as a function of serial position and task. (C) Mean proportion of errors as a function of the migration distance relative to correct temporal position. Error bars represent one unit of standard error. 
cant: verbal-preitem $[M=-.36, S D=.97 ; t(19)=1.60$, $p>1]$; verbal-postitem $[M=.11, S D=.87 ; t(19)<1]$; spatial-preitem $[M=-.27, S D=.74 ; t(19)=1.60$, $p>1]$; and spatial-postitem $[M=-.02, S D=.74$; $t(19)<1]$. In summary, accuracy was not affected by the pre- or postitem intervals.

The effect of the pre- and postitem intervals was also assessed by defining three interval ranges of $300 \mathrm{msec}$ for the pre- and postintervals. A 2 (verbal/spatial) $\times 2$ (pre-/ postitem interval) $\times 3$ (Positions 2,4 , or 6$) \times 3$ (interval ranges) ANOVA for repeated measures was conducted on the proportion of correct responses. No effect of interval was observed for any task, serial position, or type of interval (see Figure 2). A significant effect of task was found $\left[F(1,37)=28.433, M S_{\mathrm{e}}=0.704, p<.001\right]$, reflecting the better performance observed in the verbal task. The effect of serial position was also significant $[F(2,74)=$ $\left.33.926, M S_{\mathrm{e}}=0.034, p<.001\right]$. A task $\times$ serial position interaction just reached significance $[F(2,74)=3.306$, $\left.M S_{\mathrm{e}}=0.034, p<.05\right]$, due to the slightly steeper drop in performance from Serial Positions 2 to 4 in the spatial task, relative to the verbal task (see Figure 1, panel A). No other effect or interaction was significant. In conclusion, interval duration did not affect accuracy.
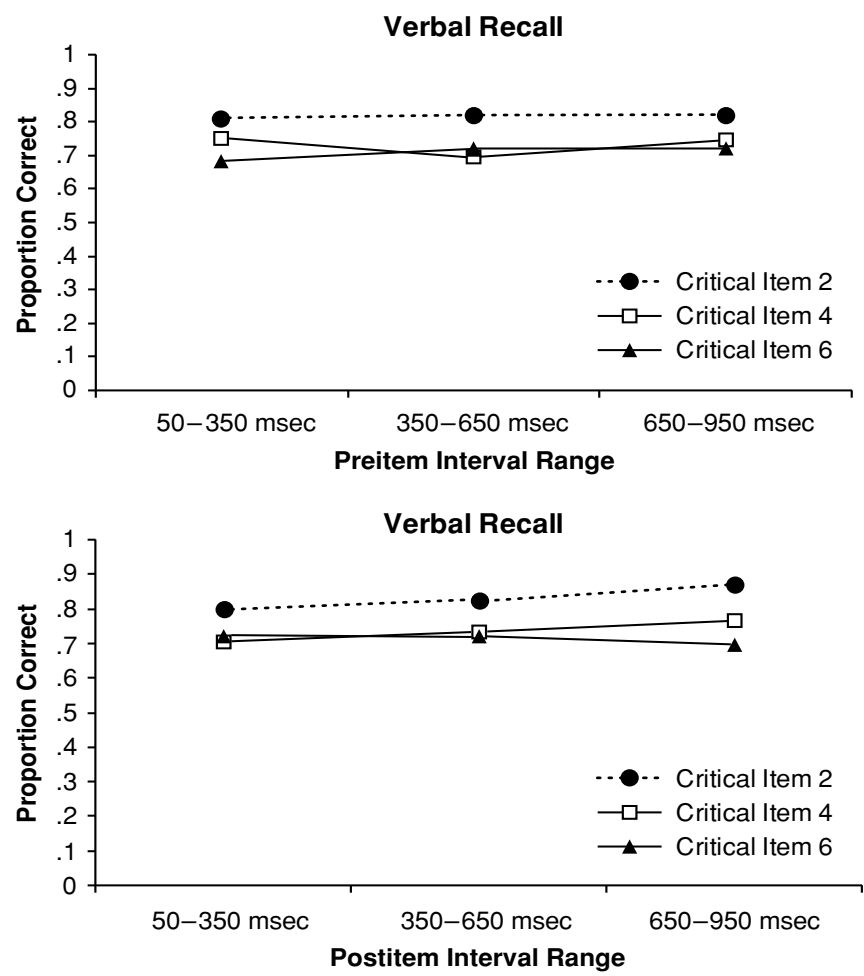

\section{Test of a Temporal Distinctiveness Model}

As was pointed out in our introduction, time-based models predict that items temporally isolated, relative to others in the list, should be better recalled than less distinctive items. To test this prediction, we compared our data with the predictions of a simple relative temporal distinctiveness model (TDM), based on the principles built into SIMPLE (Brown et al., 2005). In this model, the probability of recalling an item $i$ in the correct serial position is defined as the inverse of the temporal confusability of that item, relative to all $k$ items in the list:

$$
P_{i}=\frac{1}{\sum_{k} \operatorname{Ratio}\left(S_{i}, S_{k}\right)^{c}},
$$

where $S_{i}$ is the temporal distance of item $i$ from the point of retrieval, $c$ is a free parameter representing the steepness of the function relating psychological distance to confusability, and Ratio $\left(S_{i}, S_{k}\right)$ divides the smaller of $S_{i}$ and $S_{k}$ by the larger. On the basis of this formula, the probability of correctly recalling item $i$ will decrease when its temporal confusability with other items in the list increases; vice versa, it will rise when its temporal distinctiveness, relative to other items, increases. Our aim was not to simulate
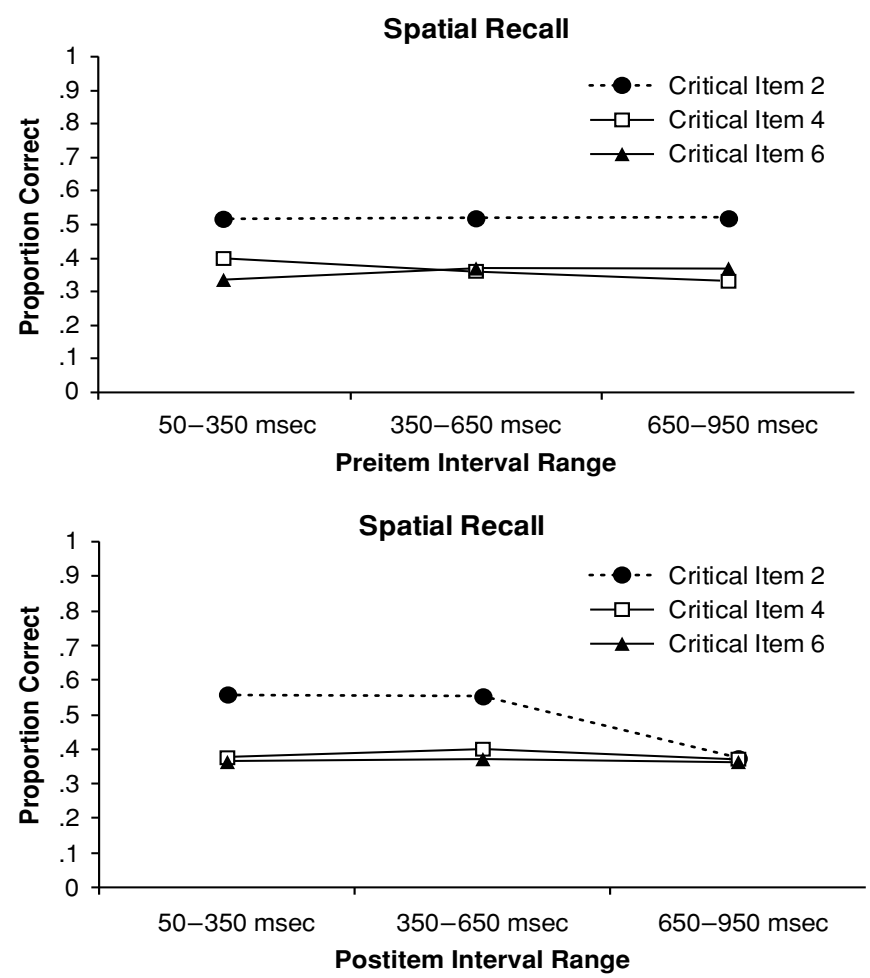

Figure 2. Mean proportion of correct recall for each critical item as a function of task (verbal or spatial) and type of interval (pre- or postitem). Left and right panels illustrate performance in the verbal and the spatial tasks, respectively. Top and bottom panels illustrate performance for the pre- and the postitem intervals, respectively. Standard error is not displayed on this figure because the values were too small to appear clearly. 
a fully fleshed version of SIMPLE (a more comprehensive assessment of SIMPLE's ability to account for data similar to ours can be found elsewhere; Lewandowsky et al., 2006) but, rather, to use a key aspect of it to contrast our data and the prediction of the temporal distinctiveness view of serial memory.

The TDM above was used to generate predictions based on the exact time intervals used in the verbal and spatial tasks for individual participants. For simplicity, we fixed the interval between the last item of a sequence and the time of recall at $1,400 \mathrm{msec}$ in the verbal task and at $1,200 \mathrm{msec}$ in the spatial task (approximately equivalent to the initiation times measured in our empirical data). The $c$ parameter was set to 30 in the verbal task and 3 in the spatial task (these values were selected because they best reproduced the serial position curves observed in our data).

Figure 3 illustrates performance as a function of preand postitem intervals in our empirical data (panel A) and the TDM for each of our two tasks. In contrast to the empirical data, TDM showed increases in performance when pre- and postitem intervals lengthened and, more sharply so, when both intervals increased. Recall accuracy (pooled across critical Serial Positions 2, 4, and 6) was analyzed in the empirical data and the TDM, using 2 (task) $\times 3$ (preitem interval: $50-350,350-650$, or $650-950 \mathrm{msec}) \times 3$ (postitem interval: $50-350,350-650$, or $650-950 \mathrm{msec}$ ) ANOVAs. Only the main effect of task was significant in the empirical data $\left[F(1,38)=30.043, M S_{\mathrm{e}}=0.329, p<\right.$ $.001]$, confirming the advantage of the verbal task over the spatial. No other effect or interaction was significant. The effect of task was captured by the TDM $[F(1,38)=$ $\left.26,246.94, M S_{\mathrm{e}}=0.0010, p<.001\right]$. Most critically, however, performance in the TDM increased with the preitem $\left[F(1,38)=259.48, M S_{\mathrm{e}}=0.0017, p<.001\right]$ and the postitem $\left[F(1,38)=112.64, M S_{\mathrm{e}}=0.0012, p<.001\right]$ intervals. The verbal task showed a relatively larger effect of both the preitem $\left[F(1,38)=6.57, M S_{\mathrm{e}}=0.0017, p<\right.$ $.01]$ and the postitem $\left[F(1,38)=10.16, M S_{\mathrm{e}}=0.0012\right.$, $p<.001]$ intervals. As can be seen in Figure 3, performance increased most when both the pre- and the postitem intervals increased, as reflected by the interaction of these two factors $\left[F(4,152)=7.48, M S_{\mathrm{e}}=0.0004, p<.001\right]$. The three-way interaction was not significant $[F(4,152)=$ $\left.1.91, M S_{\mathrm{e}}=0.0004, p>.1\right]$.

\section{DISCUSSION}

In our study, we examined (1) whether serial recall accuracy depends on the interitem time intervals at presentation, (2) whether the postitem interval mediates recall accuracy by boosting the consolidation of information in memory, and (3) whether auditory spatial stimuli would show enhanced effects of temporal distinctiveness. The study also offered the first within-participants comparison of serial recall performance in verbal and spatial auditory serial recall tasks.

A number of findings were reported. First, recall accuracy did not vary as a function of the interval preceding or following items. Second, this conclusion held regardless of the task (verbal or spatial). Even in the spatial version of the task, thought to be more dependent on efficient consolidation than is the verbal task, increasing the postitem interval did not improve performance. Third, our data could not be accounted for by a basic model of temporal distinctiveness according to which items isolated from their neighbors stand a better chance of recall. Fourth, the data conformed to the typical findings reported in other serial recall studies in which regular schedules of presentation were used: U-shaped serial position curves (e.g., Jones, Farrand, Stuart, \& Morris, 1995), a relative decrease in response latencies with serial position (Cowan et al., 1994; Kahana \& Jacobs, 2000; Maybery et al.,
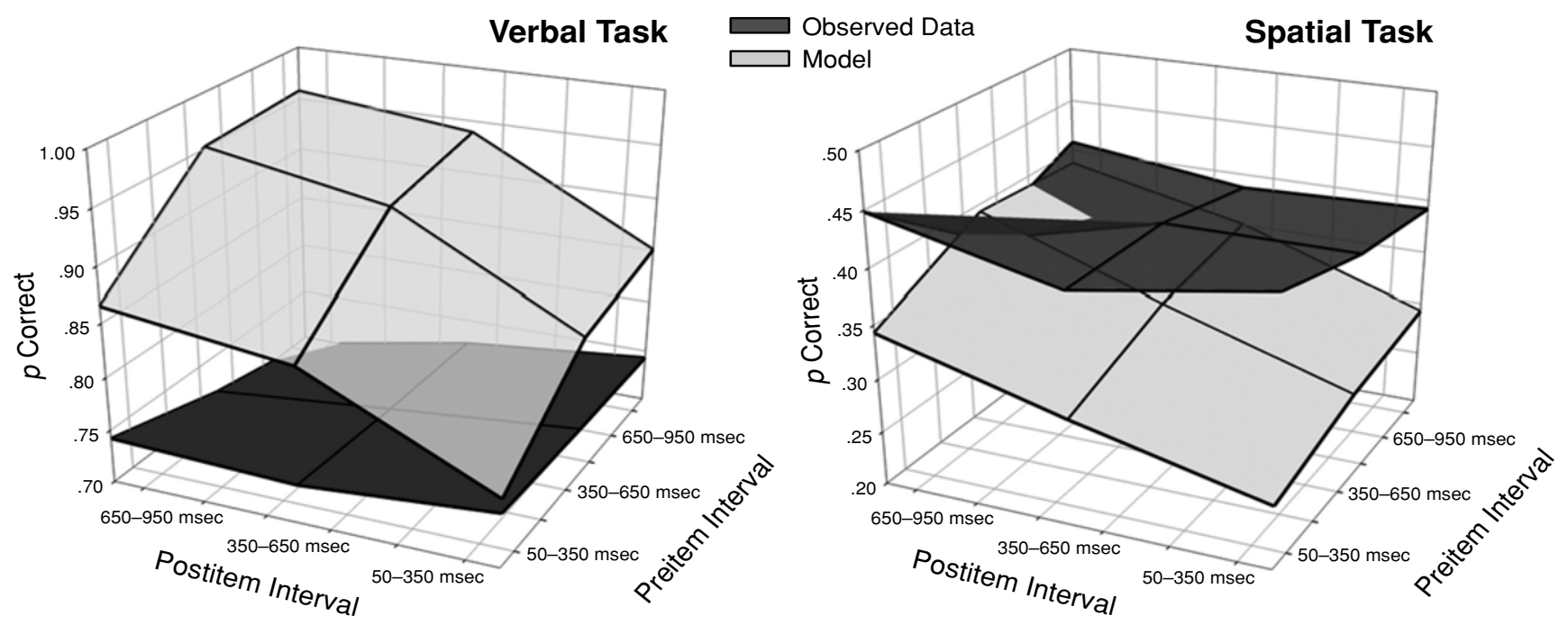

Figure 3. Mean proportion of correct recall calculated across critical Serial Positions 2, 4, and 6 as a function of task (verbal or spatial), and pre- or postitem intervals, as observed in the empirical data and as produced by a relative temporal distinctiveness model. 
2002), and a pattern of temporal migrations defined by a negatively accelerated exponential function (e.g., Brown et al., 2006; Parmentier \& Jones, 2000).

Our results in the verbal task resemble those in Lewandowsky and Brown (2005) in showing that the interval preceding an item does not predict its recall. However, and most important, they differ with regards to the effect of postitem interval: Lewandowsky and Brown found that recall accuracy increased as the postitem interval increased. We found no such effect. The characteristics of our experiment were favorable to finding such an effect, however. Indeed, we used a similar number of trials and more participants (20 in our study, against 12 in Lewandowsky $\&$ Brown's). Second, on the basis of the parameters of the hierarchical regression reported by Lewandowsky and Brown, we estimated that our power to detect an effect of postitem interval of the same size as theirs was .74.

A second important finding of the present study was that the temporal characteristics of items did not affect performance in the spatial task, in which opportunities for consolidation were thought to be especially useful. The present study is the first to compare performance for auditory stimuli in the verbal and spatial domains, using a within-participants design. As was expected, accuracy levels were lower in the spatial task than in the verbal, whereas both tasks showed primacy and recency effects, negative exponential distribution gradients, and similar response latency functions. This adds to a growing body of studies pointing out the functional similarities between verbal and spatial serial memory (Avons, 1998; Jones et al., 1995; Parmentier, Elford, \& Maybery, 2005; Parmentier \& Jones, 2000; Parmentier, Maybery, \& Jones, 2004; Parmentier, Tremblay, \& Jones, 2004; Tremblay, Macken, \& Jones, 2001; Smyth \& Scholey, 1996; Tremblay, Nicholls, Parmentier, \& Jones, 2005; Ward, Avons, $\&$ Melling, 2004). Despite the difference in task difficulty, longer postitem intervals did not benefit performance in the spatial task. In conclusion, the present study showed no support for the contention that temporal isolation, the duration of postitem intervals, or the opportunity to consolidate information benefits recall accuracy.

The absence of an effect of temporal isolation that we report adds to an increasing body of evidence calling into question the time-based view of serial memory (Henson, 1998; Lewandowsky, Duncan, \& Brown, 2004; Maybery et al., 2002; Ng \& Maybery, 2002, 2005). Whereas we used time intervals with durations similar to those used by Lewandowsky and Brown (2005), Nimmo and Lewandowsky (2005) also failed to find an effect of postitem interval on recall accuracy with longer intervals (of up to $7 \mathrm{sec}$ ). It is, therefore, unlikely that our conclusion is specific to our paradigm or our choice of intervals. Recently, Lewandowsky et al. (2006) suggested that the effect of postitem interval in Lewandowsky and Brown's study was due to grouping effects induced by intervals at certain serial positions. Signs of grouping are indeed visible in Lewandowsky and Brown's Experiment 1, in which the serial position curve showed some scalloping. In the present study, no evidence of grouping was found: Serial position curves and distribution gradients were smooth in both the verbal and the spatial tasks. In addition, the pattern of response latencies showed no mid-list peaks such as those normally observed in the presence of grouping (Maybery et al., 2002). Since we used intervals similar to those of Lewandowsky and Brown, why did we fail to find any evidence of grouping? One possible explanation may be a methodological difference between their study and ours: In their study, lists contained nine items, whereas seven-item sequences were used in ours. Participants may simply be more likely to group as a countermeasure for the increase in difficulty accompanying longer lists. On balance, however, there are now many more studies challenging the contention that recall accuracy benefits from temporal isolation (Lewandowsky et al., 2006; Nimmo \& Lewandowsky, 2005, in press) than there are studies supporting it.

Both our data and those of Nimmo and Lewandowsky (2005, in press) appear to be at odds with a number of studies reporting beneficial effects of temporal distinctiveness on serial recall accuracy (Bjork \& Whitten, 1974; Neath \& Crowder, 1990, 1996). According to the temporal distinctiveness theory, the probability of recalling an item increases as the temporal separation from the preceding or the following item increases. There is, however, an important difference between previous serial recall studies, on the one hand, and the present data, along with those in Nimmo and Lewandowsky's (2005, in press) and Lewandowsky et al.'s (2006) studies, on the other. Whereas the latter used quasirandom arrangements of intervals between items, other studies have manipulated the interitem intervals across trials (Bjork \& Whitten, 1974) or have used predictable ascending or descending interval durations (Crowder \& Neath, 1991; Neath \& Crowder, 1990, 1996). As was pointed out by Nimmo and Lewandowsky (2005, in press), this means that serial positions and interitem interval durations could not be deconfounded but, also, that participants may have engaged in strategic encoding. For example, Lewandowsky et al. (2006) have suggested that when interitem intervals are progressively expanding or shrinking, participants may choose to concentrate their effort on items that can be encoded more readily. The absence of an effect of the temporal schedule of presentation in our study calls into question the usefulness of the temporal distinctiveness theory when interitem intervals are unpredictable. It does not rule out the theory in all circumstances, however. It is reasonable to assume that the impact of temporal distinctiveness may depend on the extent to which temporal information offers cues to encode and maintain order information (e.g., by inducing temporal group boundaries). When interitem intervals vary randomly across trials, the processing of order may rely on cues other than time (e.g., positional codes). ${ }^{2}$ The relevance of temporal information was recently identified as an important factor in simulations of serial and probed recall in a modified version of SIMPLE proposed by Lewandowsky et al. (2006). In this model, the authors introduced a parameter representing the attentional weight given to the temporal dimension, extending the scope of 
SIMPLE to circumstances in which temporal distinctiveness may not be the most relevant order cue.

One possible limitation of the present study is that the postitem intervals may have been used by the participants to rehearse more than the most recent item. This may have obscured the effect of the postitem interval. Our interitem intervals were short, however, and unlikely to allow the rehearsal of several items. Moreover, Lewandowsky et al. (2006) reported similar results, irrespective of whether participants suppressed articulation or not.

In summary, our study showed that recall accuracy did not vary as a function of randomly arranged pre- or postitem intervals, calling into question the usefulness of relative time-based models in such circumstances. Although the consolidation of information in the latter may arguably offer more benefit to longer postitem intervals, no support for the contention that the postitem interval allows the consolidation of information in memory was found in our auditory verbal serial memory task (see also Nimmo \& Lewandowsky, in press) or in our, arguably more demanding, auditory spatial task.

\section{REFERENCES}

Anderson, J. R., \& Matessa, M. (1997). A production system theory of serial memory. Psychological Review, 104, 728-748.

Avons, S. E. (1998). Serial report and item recognition of novel visual patterns. British Journal of Psychology, 89, 285-308.

BJork, R. A., \& Whitten, W. B. (1974). Recency-sensitive retrieval processes in long-term free recall. Cognitive Psychology, 6, 173-189.

Brown, G. D. A., Neath, I., \& Chater, N. (2006). A ratio model of scale-invariant memory and identification. Manuscript submitted for publication.

Brown, G. D. A., Preece, T., \& Hulme, C. (2000). Oscillator-based memory for serial order. Psychological Review, 107, 121-181.

Burgess N., \& Hitch, G. (1999). Memory for serial order: A network model of the phonological loop and its timing. Psychological Review, 106, 551-581.

Cowan, N., Keller, T. A., Hulme, C., Roodenrys, S., McDougall, S., \& RACK, J. (1994). Verbal memory span in children: Speech timing clues to the mechanisms underlying age and word length effects. Journal of Memory \& Language, 33, 234-250.

EbBinghaus, H. (1885). Über das Gedächtnis: Untersuchungen zur experimentellen Psychologie. Leipzig: Duncker \& Humblot.

FARREL, S., \& LEWANDOWSKy, S. (2002). An endogenous distributed model of ordering in serial recall. Psychonomic Bulletin \& Review, 9 , 59-79.

Glenberg, A. M., \& Swanson, N. G. (1986). A temporal distinctiveness theory of recency and modality effects. Journal of Experimental Psychology: Learning, Memory, \& Cognition, 12, 3-15.

Henson, R. N. A. (1998). Short-term memory for serial order: The start-end model. Cognitive Psychology, 36, 73-137.

Jones, D., Farrand, P., Stuart, G., \& Morris, N. (1995). Functional equivalence of verbal and spatial information in serial short-term memory. Journal of Experimental Psychology: Learning, Memory, \& Cognition, 21, 1008-1018.

KAHANA, M. J., \& JACOBS, J. (2000). Interresponse time in serial recall: Effect of intraserial repetition. Journal of Experimental Psychology: Learning, Memory, \& Cognition, 26, 1188-1197.

Kubovy, M., \& Van Valkenburg, D. (2001). Auditory and visual objects. Cognition, 80, 97-126.

LASHley, K. S. (1951). The problem of serial order in behavior. In L. A. Jeffress (Ed.), Cerebral mechanisms in behavior: The Hixon symposium (pp. 112-136). New York: Wiley.

LEWANDOWSKY, S., \& BRown, G. D. A. (2005). Serial recall and presentation schedule: A micro-analysis of local distinctiveness. Memory, 13, 283-292.
Lewandowsky, S., Brown, G. D. A., Wright, T., \& Nimmo, L. M. (2006). Timeless memory: Evidence against temporal distinctiveness models of short-term memory for serial order. Journal of Memory \& Language, 54, 20-38.

Lewandowsky, S., Duncan, M., \& Brown, G. D. A. (2004). Time does not cause forgetting in short-term serial recall. Psychonomic Bulletin \& Review, 11, 771-790.

LeWAndowsky, S., \& Murdock, B. B., JR. (1989). Memory for serial order. Psychological Review, 96, 25-57.

Maybery, M. T., Parmentier, F. B. R., \& Jones, D. M. (2002). Grouping of list items reflected in the timing of recall: Implications for models of serial verbal memory. Journal of Memory \& Language, 47, 360-385.

NAIRne, J. S. (1990). A feature model of immediate memory. Memory \& Cognition, 18, 251-269.

NeATH, I. (1993). Distinctiveness and serial position effects in recognition. Memory \& Cognition, 21, 689-698.

NeAth, I. (2000). Modeling the effects of irrelevant speech on memory. Psychonomic Bulletin \& Review, 7, 403-423.

Neath, I., \& Crowder, R. G. (1990). Schedules of presentation and temporal distinctiveness in human memory. Journal of Experimental Psychology Learning, Memory, \& Cognition, 16, 316-327.

Neath, I., \& Crowder, R. G. (1996). Distinctiveness and very shortterm serial position effects. Memory, 4, 225-242.

NG, H. L. H., \& Maybery, M. T. (2002). Temporal grouping effects in short-term memory: An evaluation of time-dependent models. Quarterly Journal of Experimental Psychology, 55A, 391-424.

NG, H. L. H., \& MAYBery, M. T. (2005). Grouping in short-term memory: Do oscillators code the positions of items? Journal of Experimental Psychology: Learning, Memory, \& Cognition, 31, 175-181.

Nimmo, L. M., \& Lewandowsky, S. (2005). From brief gaps to very long pauses: Temporal isolation does not benefit serial recall. Psychonomic Bulletin \& Review, 12, 999-1004.

Nimmo, L. M., \& Lewandowsky, S. (in press). Distinctiveness revisited: Unpredictable temporal isolation does not benefit short-term serial recall of heard or seen events. Memory \& Cognition.

Parmentier, F. B. R., Elford, G., \& Maybery, M. T. (2005). Transitional information in spatial serial memory: Path characteristics affect recall performance. Journal of Experimental Psychology: Learning, Memory, \& Cognition, 31, 412-427.

Parmentier, F. B. R., \& Jones, D. M. (2000). Functional characteristics of auditory temporal-spatial short-term memory: Evidence from serial order errors. Journal of Experimental Psychology: Learning, Memory, \& Cognition, 26, 222-238.

Parmentier, F. B. R., \& Jones, D. M. (2006). The role of attentional resources in remembering auditory spatial sequences. Manuscript submitted for publication.

Parmentier, F. B. R., Maybery, M. T., \& Jones, D. M. (2004). Temporal grouping in auditory spatial serial memory. Psychonomic Bulletin \& Review, 11, 501-507.

Parmentier, F. B. R., Tremblay, S., \& Jones, D. M. (2004). Exploring the suffix effect in serial visuospatial short-term memory. Psychonomic Bulletin \& Review, 11, 289-295.

Smyth, M. M., \& Scholey, K. A. (1996). Serial order in spatial immediate memory. Quarterly Journal of Experimental Psychology, 49A, 159-177.

Tremblay, S., Macken, W. J., \& Jones, D. M. (2001). The impact of broadband noise on serial memory: Changes in band-pass frequency increase disruption. Memory, 9, 323-331.

Tremblay, S., Nicholls, A. P., Parmentier, F. B. R., \& Jones, D. M. (2005). Visual distraction and visuo-spatial memory: A sandwich effect. Memory, 13, 357-363.

Ward, G., Avons, S. E., \& Melling, L. (2005). Serial position curves in short-term memory: Functional equivalence across modalities. Memory, 13, 308-317.

\section{NOTES}

1. We thank Ian Neath for bringing this point to our attention.

2. We thank Jim Nairne for this suggestion. 
APPENDIX A

Descriptive Statistics for the Interitem Intervals

The same set of 14,400 intervals ( 20 subjects $\times 20$ trials $\times 6$ interitem intervals) was used in the verbal and the spatial tasks. Intervals were at least $50 \mathrm{msec}$ long and, at most, $950 \mathrm{msec}$ long. Across participants, the mean minimum duration was $50.6 \mathrm{msec}(S D=0.97)$, the mean maximum duration was $945.15 \mathrm{msec}(S D=3.31)$, and the mean standard deviation of intervals was $241.74 \mathrm{msec}(S D=8.60)$. The table below illustrates the distribution of the intervals across the experiment into time bins of $50 \mathrm{msec}$.

\begin{tabular}{ccc} 
Interval Range $(\mathrm{msec})$ & Proportion & Cumulative Proportion \\
\hline $50-100$ & .10 & .10 \\
$100-150$ & .08 & .18 \\
$150-200$ & .08 & .26 \\
$200-250$ & .08 & .34 \\
$250-300$ & .08 & .41 \\
$300-350$ & .07 & .48 \\
$350-400$ & .06 & .55 \\
$400-450$ & .06 & .61 \\
$450-500$ & .05 & .66 \\
$500-550$ & .05 & .72 \\
$550-600$ & .05 & .77 \\
$600-650$ & .05 & .81 \\
$650-700$ & .04 & .85 \\
$700-750$ & .03 & .89 \\
$750-800$ & .04 & .92 \\
$800-850$ & .03 & .96 \\
$850-900$ & .02 & .98 \\
$900-950$ & .02 & 1.00 \\
\hline
\end{tabular}

\section{APPENDIX B}

\section{Overall accuracy}

Omissions represented fewer than $1 \%$ of the responses in both tasks. A 2 (task) $\times 7$ (serial position) ANOVA for repeated measures on the number of correct responses confirmed the advantage of the verbal task over the spatial task $\left[F(1,19)=19.078, M S_{\mathrm{e}}=0.311, p<.001\right]$ and varied with serial position $[F(6,114)=60.281$, $\left.M S_{\mathrm{e}}=0.006, p<.001\right]$. The interaction almost reached significance $\left[F(6,114)=2.011, M S_{\mathrm{e}}=0.005, p=\right.$ .07], probably due to the slightly steeper decrease in performance with serial position in the spatial task.

\section{Response Latencies}

A 2 (task) $\times 7$ (serial position) ANOVA on the mean response times for correct responses confirmed these observations. Response latencies were longer in the spatial task than in the verbal $\left[F(1,19)=5.14, M S_{\mathrm{e}}=\right.$ $159,207.00, p<.05]$. The effect of serial position was significant $\left[F(6,114)=105.42, M S_{\mathrm{e}}=23,556.20, p<\right.$ $.001]$, as was the task $\times$ serial position interaction $\left[F(6,114)=4.72, M S_{\mathrm{e}}=14,873.20, p<.001\right]$, most likely reflecting the small inverted U-shaped function observed in the spatial task between Serial Positions 2 and 7 , as indicated by a difference in quadratic components between the two tasks across these positions $[F(1,19)=$ 5.22, $\left.M S_{\mathrm{e}}=14,039.27, p<.05\right]$.

\section{Distribution Gradients}

The percentage of errors decreased with migration distance following negatively accelerated exponential functions $\left(\%\right.$ error $=124.07 e^{-.87 x}, R^{2}=.98$, for the verbal task, and $\%$ error $=101.08 e^{-.66 x}, R^{2}=.97$, for the spatial task). Both functions differed from chance level. 